\title{
The Electrochemical Properties of Porous Carbon Derived from the Prawn as Anode for Lithium Ion Batteries
}

\author{
Xin Lian ${ }^{1}$, Qidong Li ${ }^{2}$, Yanming Zhao ${ }^{1,3, *}$, Shenghong Liu ${ }^{1}$, Huatao Liu ${ }^{2}$, Hui Zhang ${ }^{2}$ \\ ${ }^{1}$ School of Physics, South China University of Technology, Guangzhou, 510640, China \\ ${ }^{2}$ School of Material Science and Engineering, South China University of Technology, Guangzhou, \\ 510640, P. R. China \\ ${ }^{3}$ State Key Laboratory of Luminescent Materials and Devices, South China University of Technology, \\ Guangzhou, 510640, P. R. China \\ *E-mail: zhaoym@scut.edu.cn
}

Received: 12 November 2017 / Accepted: 4 January 2018 / Published: 5 February 2018

\begin{abstract}
Porous carbon materials derived from the prawn shell (PSC) and prawn meat (PMC) have been successfully fabricated by a simple "curing" method, followed by an annealing process. The PSC and PMC are well characterized by XRD, Raman, SEM and TEM. Electrochemical measurements reveal that PSC and PMC deliver high initial discharge/charge capacities of $1735 / 878 \mathrm{mAh} \mathrm{g}^{-1}$ and 1132/674 $\mathrm{mAh} \mathrm{g}^{-1}$ at $100 \mathrm{~mA} \mathrm{~g}^{-1}$ and maintain charge capacity retention of $84.2 \%$ and $40.3 \%$ after 90 cycles, respectively. Moreover, the PSC exhibits a high reversible capacity of $300 \mathrm{mAh} \mathrm{g}^{-1}$ after 50 cycles at $1000 \mathrm{~mA} \mathrm{~g}^{-1}$. The outstanding electrochemical performance of PSC and PMC is attributed to the coherent interconnected porous structure and nitrogen doping, which is beneficial for fast penetration of electrolyte, rapid diffusion of $\mathrm{Li}^{+}$and creation of numerous active sites for $\mathrm{Li}^{+}$storage.
\end{abstract}

Keywords: Prawn; porous carbon; lithium ion batteries; nitrogen doping; anode

\section{INTRODUCTION}

Lithium ion batteries (LIBs) have been considered as one of the most promising energy storage systems for portable and smart devices (e.g., MP3, cell phones and laptops) and electric vehicles (EVs, including hybrid- and plug-in EVs) [1]. It is believed that suitable electrode materials with high power/energy densities and low cost is a key to success of LIBs for their large-scale applications in EVs [2-4]. Graphite as anode for LIBs has achieved great success mainly due to cycling stability, long cycle life and low cost $[5,6]$. However, it suffers from low specific capacity, poor rate capability and risk of the formation of lithium dendrite resulted from its low working potential [7, 8]. To address these critical issues, tremendous efforts have been devoted to searching alternative anodes. 
Carbonaceous materials are ideal alternative candidates to graphite. This is mainly due to their high electric conductivity, high specific capacity and excellent chemical stability. Among the carbonaceous materials, activated carbon species derived from the abundant natural bio-precursors, such as cotton wool [9], coffee shells [10], rice husk [11], alginic acid [12], pine cone flowers [13], have drawn much attention over the past years. Such kinds of materials often possess rich porous structures and high specific surface area. In order to obtain high-performance activated carbon, several preparation methods have been developed. The common routes include: (i) the chemical activation of the biomass precursors with the use of strong chemical acid or alkaline reagent, like $\mathrm{NaOH}[14,15]$, $\mathrm{KOH}$ [16] and $\mathrm{H}_{3} \mathrm{PO}_{4}$ [17]; (ii) the physical activation via the steam or $\mathrm{CO}_{2}$ treatment [18, 19]. However, these common routes often involve the use of strong chemical reagent in the chemical activation process and need multiple or even complex preparation procedures. Therefore, to search simple and effective methods for the preparation of activation carbon from biomass has been attracted great attentions.

Marine biomasses (e.g., prawn, squid and crab) are kinds of natural abundant resource. These biomasses contain rich chitin and protein. Moreover, the activation carbon from such kinds of marine biomass with high level nitrogen content is beneficial for improving lithium storage properties [14, 15]. As aforementioned, searching a simple and effective method for the treatment of marine biomass become critically important. Herein, we have successfully employed a simple "curing" (often used in food process [20]) method to produce high-quality activated carbon from prawn. In the "curing" method, the prawn as raw material was directly placed in the $\mathrm{NaCl}$ saturated solution for "curing" treatment. During this process, $\mathrm{NaCl}$ evenly infiltrates into the tissue of the prawn, which is favorable for the subsequent formation of rich porous structures. The residual $\mathrm{NaCl}$ within the activation carbon that was carbonized from as-prepared shell and meat can be removed easily and completely by using distilled water. For the biomass composed with shell (rich in chitin) and meat (rich in protein), most reports focused on the research of biomass shells because they are often considered as "waste". Although few attentions have been paid to the carbon activated from biomass meat, it is expected that meat may also be a good candidate as anode for LIBs. Here, benefitting from rich porous structures and high nitrogen doping level, activated carbon materials derived from the prawn shell (PSC) and prawn meat (PMC) display good lithium storage properties.

\section{EXPERIMENTAL}

\subsection{Materials synthesis}

Firstly, prawn was placed in the saturated $\mathrm{NaCl}$ solution at $100{ }^{\circ} \mathrm{C}$ for $30 \mathrm{~min}$ to destruct the cell membrane activity of the prawn. This process avails the permeation of $\mathrm{NaCl}$ into the interior of cell. To promote the deep uptake of $\mathrm{NaCl}$, the prawn was transferred into a beaker with the saturated $\mathrm{NaCl}$ solution for 5 days. After that, the resulted prawn was separated into the shell (rich in chitin) and meat (rich in protein) and dried at $80^{\circ} \mathrm{C}$ in a blast oven. Then, prawn shell and meat were carbonized at $700{ }^{\circ} \mathrm{C}$ for $5 \mathrm{~h}$ under an atmosphere of $\mathrm{H}_{2} / \mathrm{Ar}$ (30/70 vol. \%). In order to remove the insoluble metal 
ion (i.e., $\mathrm{Ca} / \mathrm{Ca}^{2+}$ ) as well as the soluble ions (e.g., $\mathrm{K}^{+}, \mathrm{Na}^{+}, \mathrm{Cl}^{-}$), the resulted samples were washed completely with $1 \mathrm{M} \mathrm{HCl}$ and deionized water. Finally, the black products from prawn shell (PSC) and prawn meat (PMC) were collected by centrifuging at a speed of $14000 \mathrm{rpm}$ with Allegra X-22 Centrifuge (Beckman Coulter, USA) and dried at $80^{\circ} \mathrm{C}$ in vacuo.

\subsection{Sample Characterization}

Powder X-ray diffraction (XRD) patterns and Raman spectroscopy of the PSC and PMC were performed on a Bruker D8 Advance Diffractometer and LabRAM Aramis, respectively. The morphologies of the PSC and PMC were confirmed by field-emission scanning electron microscopy (FE-SEM, Nova NanoSEM430) and transmission electron microscope (TEM, FEI (Tecnai 20 G2). Xray photoelectron spectroscopy (XPS) was measured using a Kratos Axis Ultra spectrometer. The centrifugal process was performed on an Allegra X-22 Centrifuge (Beckman Coulter, USA).

\subsection{Electrochemical measurements}

Electrochemical performance of the PSC and PMC samples was measured in coin-cell using a battery tester system (Land ${ }^{\circledR}$ CT2001A, China). The coin type cells were fabricated in a Mikrouna glove box with ultra-high-purity argon. The electrodes were prepared by mixing the active materials (i.e. PSC and PMC), polyvinylidene fluoride (PVDF) and acetylene black (AC) in a weight ratio of $7: 1: 2$. The mixing solvent is $\mathrm{N}$-methyl-2-pyrrolidone. Then, the resulted slurry was uniformly coated on $\mathrm{Cu}$ foil and then placed in a vacuum oven at $80^{\circ} \mathrm{C}$ overnight. The mass loading on the electrode was $\sim 2 \mathrm{mg} \mathrm{cm}^{-2}$. The coin-cells were fabricated by lithium metal foil as the counter electrode, Celgard 2320 as separator, the resulted electrode as working electrode and $1 \mathrm{M} \mathrm{LiPF}_{6}$ in ethylene carbonate (EC): dimethyl carbonate (DMC) 1:1 (vol.\%) as the electrolyte. Electrochemical impedance spectroscopy (EIS) was performed on an AUTOLAB PGSTAT302N (Metrohm, Netherlands).

\section{RESULTS AND DISCUSSIONS}

The X-ray diffraction (XRD) patterns of PSC and PMC are shown in Fig. 1a, where two broad diffraction peaks around $24^{\circ}$ and $43^{\circ}$ for both PSC and PMC samples are corresponding to characteristic peaks of (002) and (100) of amorphous carbon, respectively. The interlayer d-spacing of about $0.364 \mathrm{~nm}$ for (002) of PSC and PMC is higher than that for graphite $(0.335 \mathrm{~nm})$, which should be beneficial for lithium ions transportation. Fig. 1b shows Raman spectra of PSC and PMC. As shown in Fig. 1b, two characteristic peaks of carbon centered at $1340 \mathrm{~cm}^{-1}$ (D band) and $1590 \mathrm{~cm}^{-1}$ (G band) can be observed. The $\mathrm{D}$ band and $\mathrm{G}$ band are associated with the defective and disordered structures and the in-plane vibrations of carbon atoms with $\mathrm{sp}^{2}$ electronic configuration in graphitic phase respectively $[21,22]$. The intensity ratio of $\mathrm{I}_{\mathrm{D}} / \mathrm{I}_{\mathrm{G}}$ for PSC $(0.99)$ is higher than that for PMC $(0.85)$, indicating that more defects existing in PSC. 

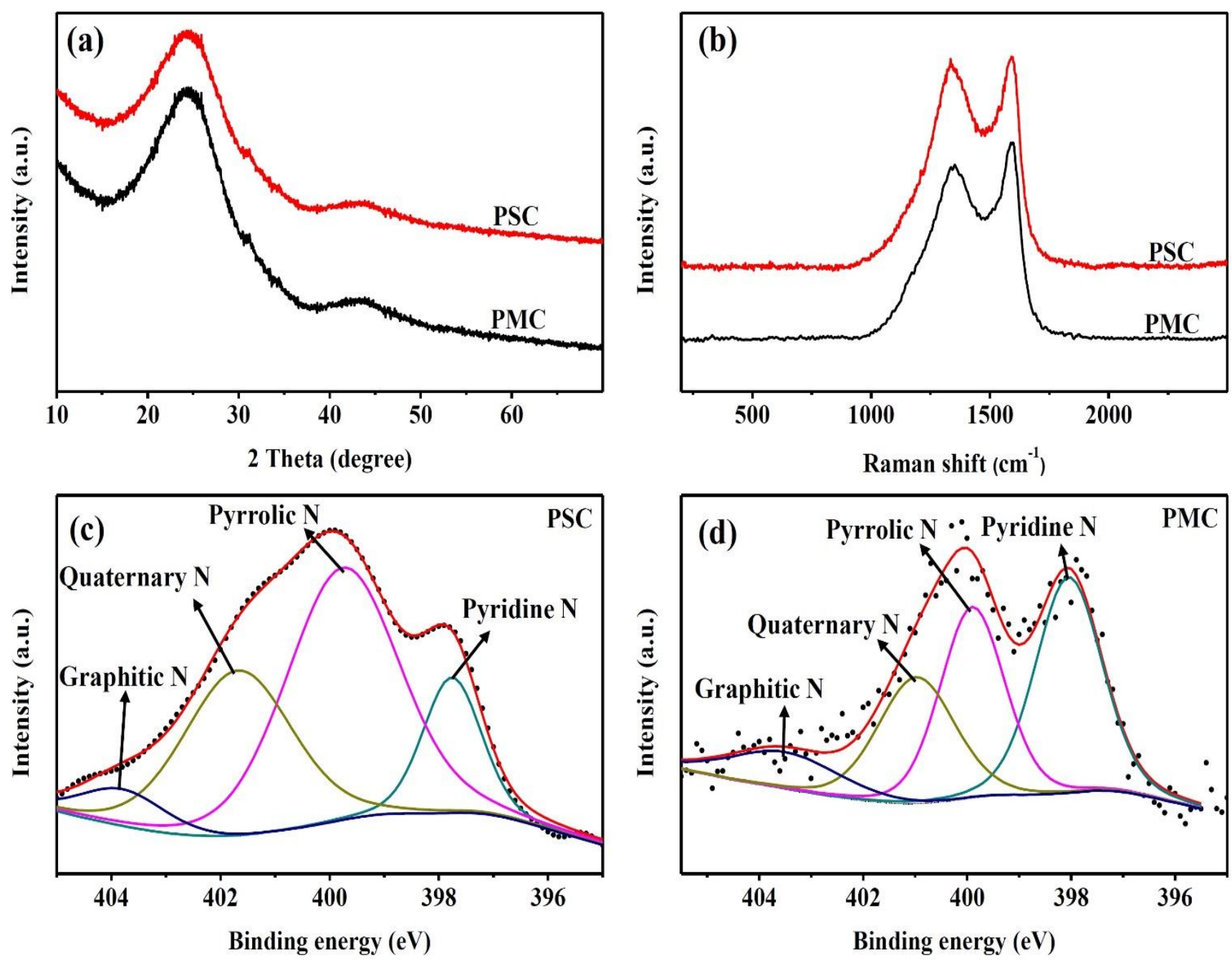

Figure 1. (a) XRD patterns and (b) Raman spectra of PSC and PMC, and high resolution XPS N 1s peak of (c) PSC and (d) PMC.

It is well known that nitrogen doping to carbon (N-C) could lead N-C with the enhanced lithium ion storage properties [23, 24]. This is mainly due to the higher electronegativity of nitrogen than that of carbon, and additional active sites for lithium ions storage. In order to identify the nitrogen states of PSC and PMC, XPS of PSC and PMC was carried out as shown in Fig. 1c-d. As can be seen, the nitrogen peaks for PSC and PMC can be further convoluted into graphitic $\mathrm{N}(403.8 \pm 0.2 \mathrm{eV})$, quaternary $\mathrm{N}(400.8 \pm 0.2 \mathrm{eV})$, pyrrolic $\mathrm{N}(399.7 \pm 0.2 \mathrm{eV})$ and pyridinic $\mathrm{N}(398.0 \pm 0.2 \mathrm{eV})$. This result is consistent with the previous reported data [17, 25].

The SEM and TEM images of PSC and PMC shown in Fig. 2 illustrate that both PSC and PMC have porous structures (Fig. 2a-b). PSC has smaller and much uniform pores with a diameter of $\sim 50$ $\mathrm{nm}$ (Fig. 2c) if one compare it with that of PMC. Generally, the 3D porous network can provide quick penetration of electrolyte and fast diffusion of lithium ions, and large surface area for lithium ions storage. Furthermore, the detailed structural information of PSC was further confirmed by HRTEM and SAED. As shown in Fig. 2d, the PSC shows the amorphous pattern, which agrees well with the XRD results. 

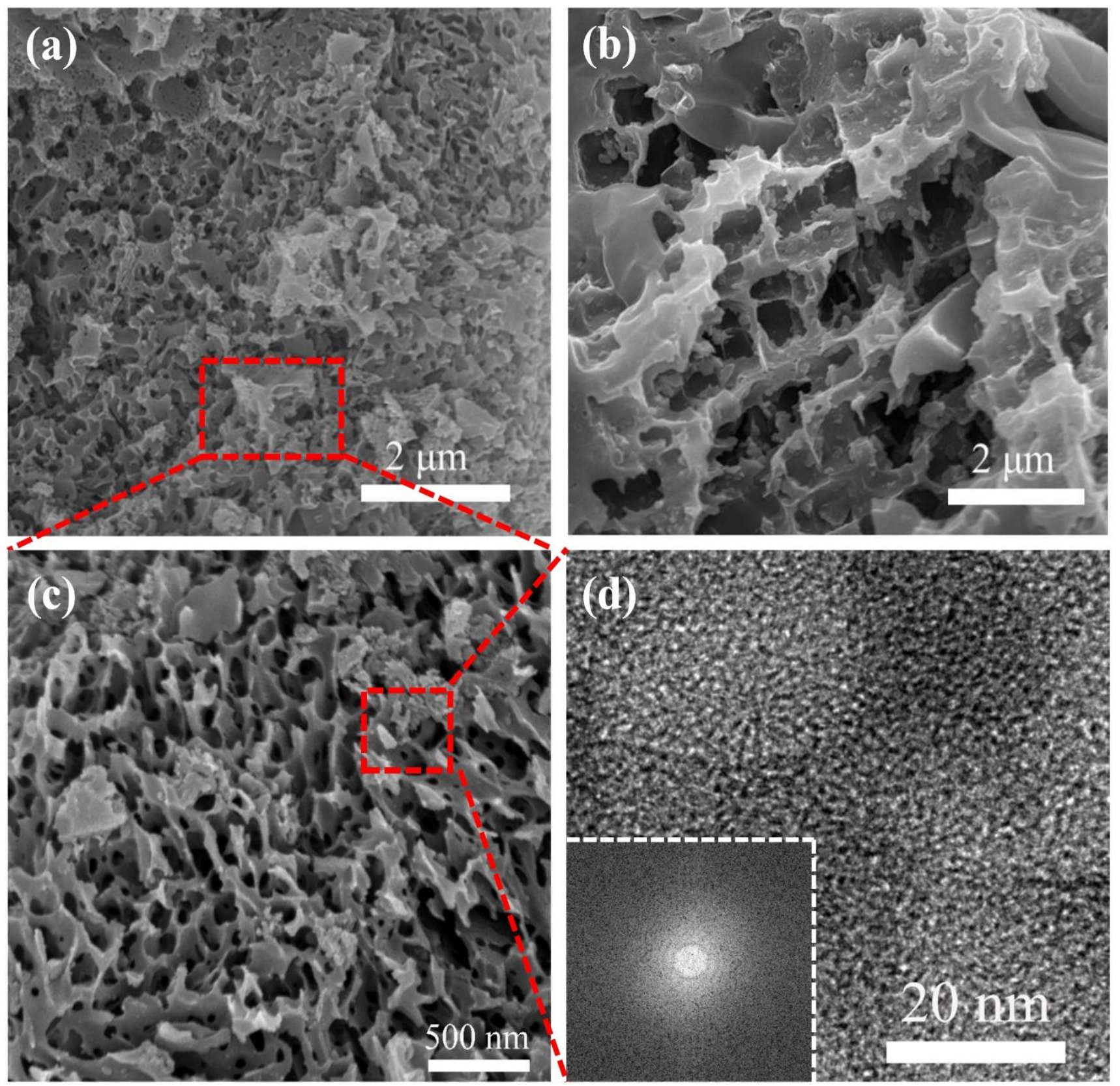

Figure 2. SEM images of (a, c) PSC and (b) PMC. (d) HRTEM image of PSC. Inset of Fig. 2d: Selected area electron diffraction (SAED).

The discharge-charge curves of PSC and PMC (Fig. 3a-b) for initial 3 cycles at $30 \mathrm{~mA} \mathrm{~g}^{-1}$ in the voltage between 0.005 and $3.0 \mathrm{~V}$ agree well with typical carbonaceous materials as anodes for LIBs [23-25]. As shown in Fig.3a, the PSC and PMC exhibit high initial discharge/charge capacities of $1803 / 910 \mathrm{mAh} \mathrm{g}^{-1}$ and 1200/694 $\mathrm{mAh} \mathrm{g}^{-1}$, corresponding to initial Coulombic efficiencies (CEs) of $50.4 \%$ and $57.8 \%$, respectively. The formation of solid electrolyte interface (SEI) on the surface of PSC and PMC should be a key role for the relatively low initial CE [26]. After the first cycle, the Coulombic efficiencies increased quickly to $91.0 \%$ (PSC) and 92.7\% (PMC) for the second cycle, 93.7\% (PSC) and 94.5\% (PMC) for the third cycle, and eventually to hover nearly $100 \%$ afterward. As shown in the insets of Fig. 3a-b, the results from electrochemical voltage spectroscopy (EVS) 
differential capacity curves of PSC and PMC for the first three cycles are almost consistent with the corresponding discharge-charge profiles (Fig. 3a-b). It should be noted that, there was a distinct oxidation peak centered at $\sim 1.1 \mathrm{~V}$ (Fig. 3a), most likely corresponding to delithiation process of Lioxygen containing functional groups. The highly overlapped peaks during the following cycles further indicate good reversibility of PSC and PMC (especially for PSC).
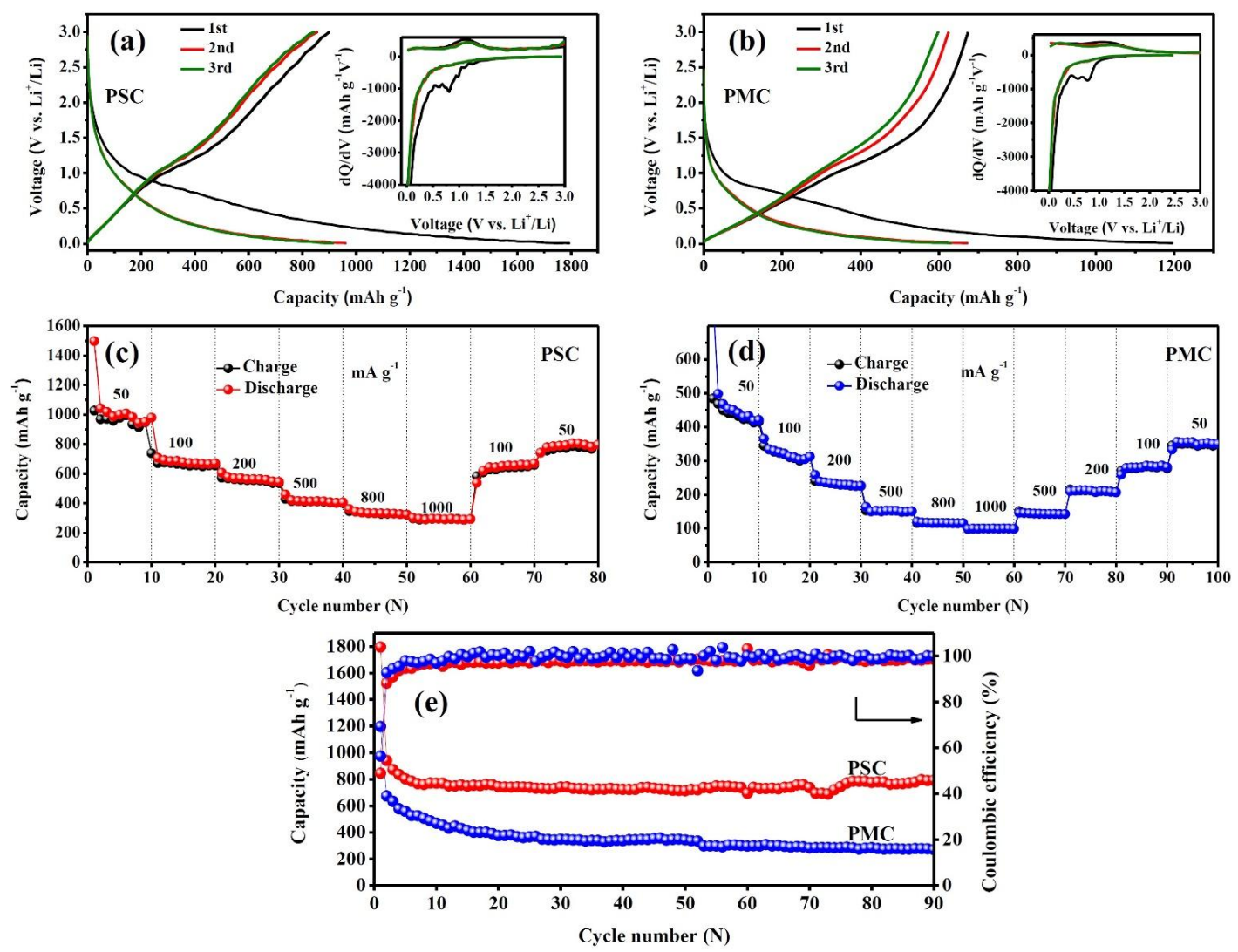

Figure 3. Discharge-charge curves of (a) PSC and (b) PMC for initial three cycles at $30 \mathrm{~mA} \mathrm{~g}^{-1}$, rate capability of (c) PSC and (d) PMC at different current densities; and (e) cycling performance of PSC and PMC at $100 \mathrm{~mA} \mathrm{~g}^{-1}$. Insets of Fig. 3a-b are the corresponding EVS differential capacity data.

The rate capabilities of PSC and PMC are evaluated at various current densities ranging from 50 to $1000 \mathrm{~mA} \mathrm{~g}^{-1}$ between 0.005 and $3.0 \mathrm{~V}$ (Fig. 3c-d). As the current densities increased from 50 to $1000 \mathrm{~mA} \mathrm{~g}^{-1}$, the PSC shows excellent rate capability with high average reversible capacities of 950, $674,572,430,347$ and $300 \mathrm{mAh} \mathrm{g}^{-1}$ at 50,100, 200, 500, 800 and $1000 \mathrm{~mA} \mathrm{~g}^{-1}$, respectively, which are higher than those for PMC (420, 345, 241, 153, 117 and $\left.100 \mathrm{mAh} \mathrm{g}^{-1}\right)$. This can be attributed to more rich and uniform nanoporous structures of PSC than that of PMC, as well as its higher nitrogen doping level. Since the current density is set back to $50 \mathrm{~mA} \mathrm{~g}^{-1}$, the PSC and PMC still demonstrate excellent reversibility and recoverability. Fig. 3e shows the cycling performance of the PSC and PMC at 100 $\mathrm{mA} \mathrm{g}^{-1}$ for 90 cycles. As can be seen, the PSC exhibits more excellent stability with the reversible capacity retention of $\sim 84.2 \%$ (PSC) after 90 cycles, which is higher than that for PMC $(40.3 \%)$. 
Table 1. Comparison of the carbon derived from biomass for lithium ion batteries with previous reported studies.

\begin{tabular}{|c|c|c|c|c|}
\hline $\begin{array}{l}\text { Biomass } \\
\text { precursor }\end{array}$ & Activation method & $\begin{array}{l}\text { Temperature } \\
\left({ }^{\circ} \mathrm{C}\right)\end{array}$ & Capacity $\left(\mathrm{mAh} \mathrm{g}^{-1}\right)$ & Ref. \\
\hline $\begin{array}{l}\text { Prawn shell (I) } \\
\text { Prawn meat } \\
\text { Cotton wool }\end{array}$ & $\begin{array}{c}\mathrm{NaCl} \\
\text { One step pyrolysis } \\
\text { Multi step pyrolysis }\end{array}$ & $700-1100$ & $\begin{array}{c}950 \text { at } 0.05 \mathrm{~A} \mathrm{~g}^{-1}, 300 \text { at } 1 \mathrm{~A} \mathrm{~g}^{-1} \\
420 \text { at } 0.05 \mathrm{~A} \mathrm{~g}^{-1}, 100 \text { at } 1 \mathrm{~A} \mathrm{~g}^{-1} \\
470 \\
600\end{array}$ & $\begin{array}{c}\text { This } \\
\text { work } \\
\text { [9] }\end{array}$ \\
\hline Coffee shells & $\begin{array}{l}\text { Untreated } \\
\text { KOH-treated }\end{array}$ & $\begin{array}{l}800,900 \\
800,900\end{array}$ & $\begin{array}{l}524,603 \text { at } 0.2 \mathrm{C} \text { of the } 1^{\text {st }} \text { discharge } \\
1150,1200 \text { at } 0.2 \mathrm{C} \text { of the } 1^{\mathrm{st}} \text { discharge }\end{array}$ & {$[10]$} \\
\hline Rice husk & $\begin{array}{l}\text { Hydrothermal } \\
\text { carbonization }\end{array}$ & $180-250$ & $\begin{array}{l}403 \text { at } 0.2 \mathrm{C}(100 \text { cycles }) \\
137 \text { at } 10 \mathrm{C}\end{array}$ & {$[11]$} \\
\hline Prawn shell (II) & $\mathrm{NaOH}$-treated & 750 & $\begin{array}{c}740 \text { at } 0.1 \mathrm{~A} \mathrm{~g}^{-1}(150 \text { cycles }) \\
147 \text { at }^{2 \mathrm{~A} \mathrm{~g}^{-1}}\end{array}$ & {$[14]$} \\
\hline Ox horns & $\mathrm{KOH}$-treated & 700 & $\begin{array}{l}1181 \text { at } 0.1 \mathrm{~A} \mathrm{~g}^{-1} \\
304 \text { at } 5 \mathrm{~A} \mathrm{~g}^{-1}\end{array}$ & {$[16]$} \\
\hline Rice straw & $\mathrm{KOH}$-treated & 800 & $\begin{array}{c}986 \text { of the } 1^{\text {st }} \text { cycle at } 0.1 \mathrm{C} \\
257 \text { at } 2 \mathrm{C}\end{array}$ & {$[27]$} \\
\hline Fish scale & $\mathrm{KOH}$-treated & 850 & $\begin{array}{l}500 \text { at } 0.075 \mathrm{~A} \mathrm{~g}^{-1} \\
450 \text { at } 0.2 \mathrm{~A} \mathrm{~g}^{-1}\end{array}$ & {$[28]$} \\
\hline Wheat straw & $\mathrm{KOH}$ activation & 700 & $\begin{array}{l}975 \text { at } 0.37 \mathrm{~A} \mathrm{~g}^{-1} \\
731 \text { at } 1.85 \mathrm{~A} \mathrm{~g}^{-1} \\
664 \text { at } 3.7 \mathrm{~A} \mathrm{~g}^{-1}\end{array}$ & {$[29]$} \\
\hline Human hair (I) & $\mathrm{KOH}$-treated & 800 & $\begin{array}{l}700 \text { at } 0.05 \mathrm{~A} \mathrm{~g}^{-1} \\
610 \text { at } 0.1 \mathrm{~A} \mathrm{~g}^{-1}\end{array}$ & {$[30]$} \\
\hline Human hair (II) & $\begin{array}{l}\mathrm{HCl} \text { pretreatment, } \\
\mathrm{KOH} \text { activation }\end{array}$ & 700 & $\begin{array}{l}1331 \text { at } 0.1 \mathrm{~A} \mathrm{~g}^{-1} \\
470 \text { at } 5 \mathrm{~A} \mathrm{~g}^{-1} \\
205 \text { at } 10 \mathrm{~A} \mathrm{~g}^{-1}\end{array}$ & [31] \\
\hline Egg white (I) & Untreated & 600 & 580 at $0.005 \mathrm{~A} \mathrm{~g}^{-1}$ & {$[32]$} \\
\hline Egg white (II) & Templating method & $650-850$ & $\begin{array}{l}1780 \text { of the } 2^{\text {nd }} \text { cycle at } 0.1 \mathrm{~A} \mathrm{~g}^{-1} \\
205 \text { at } 4 \mathrm{~A} \mathrm{~g}^{-1}\end{array}$ & {$[33]$} \\
\hline Honey & Templating method & $700-900$ & $\begin{array}{c}1359 \text { at } 0.1 \mathrm{~A} \mathrm{~g}^{-1} \text { (after } 10 \text { cycles) } \\
722 \text { at } 1 \mathrm{~A} \mathrm{~g}^{-1} \text { (after } 200 \text { cycles) } \\
390 \text { at } 5 \mathrm{~A} \mathrm{~g}^{-1}\end{array}$ & {$[34]$} \\
\hline Gelatin & Templating method & $700-900$ & $\begin{array}{l}1200 \text { at } 0.1 \mathrm{~mA} \mathrm{~cm}^{-1} \\
400 \text { at } 0.8 \mathrm{~mA} \mathrm{~cm}^{-1}\end{array}$ & {$[35]$} \\
\hline
\end{tabular}

The comparison of the carbon derived from biomass for lithium ion batteries with previous reported studies is included in Table 1, where the PSC and PMC fabricated by a facile "curing" method here exhibit comparative high electrochemical performance. Without involving the strong chemical reagent (e.g. $\mathrm{KOH}$ and $\mathrm{NaOH}$ ) [10, 14, 16, 27-31] during the synthesis route as well as avoiding the tedious preparation procedures in the templating method [33-35], the "curing" method adopted here will present a simple and cost-effective method for the preparation of activation carbon from other biomass. 

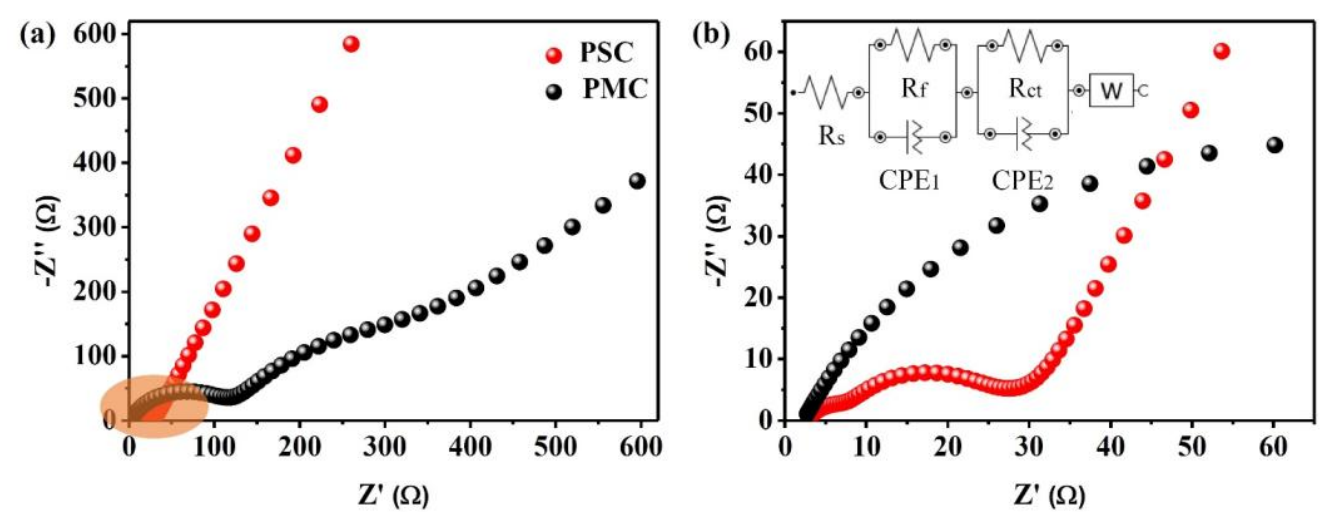

Figure 4. (a, b) EIS plots of PSC and PMC measured after 3 cycles. Inset of Fig. 4b: the equivalent circuit model for EIS analysis.

In order to understand the transport kinetics of the PSC and PMC electrodes, EIS measurements are shown in Figure 4. After three discharge-charge cycles and then rest for 3 hours, the cells were measured at $100 \mathrm{~mA} \mathrm{~g}^{-1}$ in the voltage range of 0.005-3 V. As shown in Fig. 4a-b, the PSC and PMC cells show typical Nyquist plots consisting of two depressed semicircles in the high- and medium-frequency regions and a sloping straight line in the low-frequency region. The equivalent circuit model was fabricated in the inset of Fig. 4b. The fabricated model includes internal resistance $\left(\mathrm{R}_{\mathrm{s}}\right)$ in the high- and medium-frequency region, two constant phase element $\left(\mathrm{CPE}_{1}, \mathrm{CPE}_{2}\right)$, SEI resistance $R_{f}$, charge transfer resistance $\left(R_{c t}\right)$ in the medium/low frequency region, and Warburg impedance $(\mathrm{W})$ in the unclear $\sim 45^{\circ}$ inclined line in the low-frequency region. The $\mathrm{R}_{\mathrm{ct}}$ is a key indicator of charge-transfer kinetics, which is approximately equal to the numerical value of the $2^{\text {nd }}$ semicircle. As a result, the PSC shows the lower charge transfer resistance $(\sim 16 \Omega)$ than PMC $(\sim 120 \Omega)$, which is consistent with electrochemical performance.

\section{CONCLUSIONS}

Amorphous and porous carbon derived from the prawn shell (PSC) and prawn meat (PMC) have been successfully fabricated by a simple "curing" method, followed by an annealing process. Benefitting from the rich porous structures and high nitrogen doping content, the PSC and PMC deliver high initial discharge/charge capacities of $1735 / 878 \mathrm{mAh} \mathrm{g}^{-1}$ and 1132/674 $\mathrm{mAh} \mathrm{g}^{-1}$ at $100 \mathrm{~mA}$ $\mathrm{g}^{-1}$ and retain the charge capacity retention of $84.2 \%$ and $40.3 \%$ after 90 cycles, respectively. Moreover, the PSC exhibits a high discharge capacity of $300 \mathrm{mAh} \mathrm{g}^{-1}$ after 50 cycles at $1000 \mathrm{~mA} \mathrm{~g}^{-1}$. The excellent electrochemical performance of porous carbonaceous materials derived from the prawn (especially PSC) is attributed to the coherent interconnected porous structure that effectively make it for quick penetration of electrolyte, rapid diffusion of $\mathrm{Li}^{+}$and numerous active sites for $\mathrm{Li}^{+}$storage.

\section{ACKNOWLEDGEMENTS}

The NSFC funding (No. 51672086 \& 51372089, China) and the STBG foundation (No. 2017B030308005, China) are greatly appreciated. 


\section{References}

1. M. Armand, J.M. Tarascon, Nature, 451 (2008) 652.

2. J.B. Goodenough, Y. Kim, Chem. Mater., 22 (2009) 587.

3. J. Xu, S. Dou, H. Liu, L. Dai, Nano Energy, 2 (2013) 439.

4. C. Liang, M. Gao, H. Pan, Y. Liu, M. Yan, J. Alloys Compd., 575 (2013) 246.

5. T. Tran, J. Feikert, X. Song, K. Kinoshita, J. Electrochem. Soc., 142 (1995) 3297.

6. S. Yang, X. Feng, L. Zhi, Q. Cao, J. Maier, K. Müllen, Adv. Mater., 22 (2010) 838.

7. S.S. Zhang, J. Power Sources, 161 (2006) 1385.

8. B. Simon, S. Flandrois, K. Guerin, A. Fevrier-Bouvier, I. Teulat, P. Biensan, J. Power Sources, 81 (1999) 312.

9. E. Peled, V. Eshkenazi, Y. Rosenberg, J. Power Sources, 76 (1998) 153.

10. Y.J. Hwang, S.K. Jeong, K.S. Nahm, J.S. Shin, A.M. Stephan, J. Phys. Chem. Solids, 68 (2007) 182.

11. L. Wang, Z. Schnepp, M.M. Titirici, J. Mater. Chem. A, 1 (2013) 5269.

12. X.L. Wu, L.L. Chen, S. Xin, Y.X. Yin, Y.G. Guo, Q.S. Kong, Y.Z. Xia, Chemsuschem, 3 (2010) 703.

13. G. Nagaraju, J.H. Lim, S.M. Cha, J.S. Yu, J. Alloys Compd., 693 (2017) 129.

14. I. Elizabeth, B.P. Singh, S. Trikha, S. Gopukumar, J. Power Sources, 329 (2016) 412.

15. F. Gao, J. Qu, Z. Zhao, Z. Wang, J. Qiu, Electrochim. Acta, 190 (2016) 1134.

16. J. Ou, Y. Zhang, L. Chen, Q. Zhao, Y. Meng, Y. Guo, D. Xiao, J. Mater. Chem. A, 3 (2015) 6534.

17. J. Qu, C. Geng, S. Lv, G. Shao, S. Ma, M. Wu, Electrochim. Acta, 176 (2015) 982.

18. F. Rodriguez-Reinoso, M. Molina-Sabio, M. Gonzalez, Carbon, 33 (1995) 15.

19. T. Zhang, W.P. Walawender, L. Fan, M. Fan, D. Daugaard, R. Brown, Chem. Eng. J., 105 (2004) 53.

20. I. Siró, C. Vén, C. Balla, G. Jónás, I. Zeke, L. Friedrich, J. Food. Eng., 91 (2009) 353.

21. J. Xu, I.Y. Jeon, J.M. Seo, S. Dou, L. Dai, J.B. Baek, Adv. Mater., 26 (2014) 7317.

22. W. Guo, X. Li, J. Xu, H.K. Liu, J. Ma, S.X. Dou, Electrochim. Acta, 188 (2016) 414.

23. J. Xu, Y. Lin, J.W. Connell, L. Dai, Small, 11 (2015) 6179.

24. J. Xu, J. Mahmood, Y. Dou, S. Dou, F. Li, L. Dai, J.B. Baek, Adv. Mater., 29 (2017).

25. Z. Li, Z. Xu, X. Tan, H. Wang, C.M. Holt, T. Stephenson, B.C. Olsen, D. Mitlin, Energy Environ. Sci., 6 (2013) 871.

26. M. Winter, J.O. Besenhard, M.E. Spahr, P. Novák, Adv. Mater., 10 (1998) 725.

27. F. Zhang, K. Wang, G. Li, J. Chen, Electrochem. Commun., 11 (2009) 130.

28. V. Selvamani, R. Ravikumar, V. Suryanarayanan, D. Velayutham, S. Gopukumar, Electrochim. Acta, $182(2015) 1$.

29. L. Chen, Y. Zhang, C. Lin, W. Yang, Y. Meng, Y. Guo, M. Li, D. Xiao, J. Mater. Chem. A, 2 (2014) 9684.

30. K. Saravanan, N. Kalaiselvi, Carbon, 81 (2015) 43.

31. J. Ou, Y. Zhang, L. Chen, H. Yuan, D. Xiao, Rsc Adv., 4 (2014) 63784.

32. X. Liu, M. Wen, Y. Zhao, Y. Dong, Q. Fan, Q. Kuang, Q. Li, Rsc Adv., 6 (2016) 80986.

33. Z. Li, Z. Xu, X. Tan, H. Wang, C.M. Holt, T. Stephenson, B.C. Olsen, D. Mitlin, Energy Environ. Sci., 6 (2013) 871.

34. Y. Zhang, L. Chen, Y. Meng, J. Xie, Y. Guo, D. Xiao, J. Power Sources, 335 (2016) 20.

35. Y. Mao, H. Duan, B. Xu, L. Zhang, Y. Hu, C. Zhao, Z. Wang, L. Chen, Y. Yang, Energy Environ. Sci., 5 (2012) 7950.

(C) 2018 The Authors. Published by ESG (www.electrochemsci.org). This article is an open access article distributed under the terms and conditions of the Creative Commons Attribution license (http://creativecommons.org/licenses/by/4.0/). 